\title{
BIOCOMPONENT-BASED QUALITY IMPROVEMENT OPPORTUNITIES OF BINDERS FOR ROAD CONSTRUCTION
}

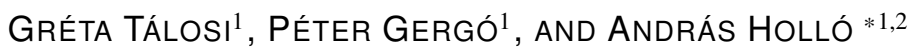 \\ ${ }^{1}$ Department of MOL Hydrocarbon and Coal Processing, Institute of Chemical and Process Engineering, \\ University of Pannonia, Egyetem u. 10, Veszprém, H-8200, HUNGARY \\ ${ }^{2}$ Downstream R\&D, MOL Plc., Olajmunkás u. 2, Százhalombatta, H-2440, HUNGARY
}

\begin{abstract}
In our experimental work, stabilised pinewood-based fast pyrolysis bio-oil and the linear block copolymer styrene butadiene styrene (SBS) were used as additives in bitumen used for road construction (Penetration Grade 50/70) to produce a higher-performance asphalt binder. Our aim was to investigate the modifying effect of the biocomponent on bituminous binders and prepare a comparative analysis. In order to characterize our samples, conventional and rheological measurements were performed. It was concluded that the biocomponent by itself cannot provide a favourable bituminous binder with beneficial mechanical properties, however, a favourable solution may be achieved by combining it with the block copolymer SBS. Based on our test results, stabilised pinewood-based fast pyrolysis bio-oil could be blended with the examined bituminous binders up to concentrations of $10 \mathrm{w} / \mathrm{w} \%$ resulting in good bitumen quality.
\end{abstract}

Keywords: bitumen 50/70, polymer modified bitumen, biocomponent, quality improvement

\section{Introduction}

The stricter demands of road construction has brought about the application of new and high performance, albeit expensive, binders (e.g. polymer modified bitumen). Thus, the development of alternative, high-quality but cheaper bitumen for road construction has become an intensively researched area [1-5].

Another aspect is that in line with sustainable development, the use of alternative materials derived from nonfossil sources, e.g. biomass or waste, can be a long-term option for the partial replacement of bitumens derived from crude oil. A further issue is that the production of low carbon fuels in the future might reduce the demand for refining crude oil, which could result in a lack of supply in the bitumen market as well. Many researchers have found that different biomass-derived oils could be suitable components for blending, substituting for and modifying bituminous binders [6]. The raw materials of the processed biomass that produce bio-oils include microalgae [7], animal waste [8,9], maize [10], garden waste [11], tea residue [12], coffee residue [13], rapeseed [14], and soybean [15]. The utilisation of these bio-oils can be beneficial following proper treatment, since these materials could increase the rutting performance of bituminous binders. These studies show that the utilisation of renewable materials can be very promising [16].

Many researchers have studied the modifying effect

*Correspondence: ahollo@mol.hu of different wood-based bio-oils. Peralta et al. examined the application of red oak residues as direct alternative binders and to reduce the environmental impact of bituminous binders [17-19]. Grilli et al. used pinewood biooil [20], Jiménez del Barco-Carrión et al. used pine resin $[21,22]$ and Lei et al. used bio-oil derived from wood as a rejuvenator [23]. Raouf and Williams investigated the utilisation options of oak wood bio-oil [24]. Cooper et al. [25], Ball et al. [26], and Bearsley and Haverkamp blended bio-oil originated pine derived tall oil as a bitumen extender $[27,28]$. Gondim et al. studied the effect of plant sap from a "Petroleum Plant" [29]. Yang et al. examined bio-oils derived from waste wood resources as bitumen modifiers and extenders [30].

In summary, bio-oils typically have a softening effect, which improves their performance at low and intermediate temperatures but impairs their high-temperature performance. This negative impact can be mitigated, e.g. by the addition of crumb rubber or other polymers.

The application of stabilised wood-based pyrolysis bio-oil as an additive for bitumen binders has been intensively researched but remains a field of future bitumen production that is yet to be clarified. The utilisation of polymer modified bitumen is widespread but the modifying effect of stabilised wood-based pyrolysis bio-oil on polymer modified bitumen has yet to be clearly defined. Thus, our target was to investigate the effect of stabilised pinewood-based fast pyrolysis bio-oil on the characteristics of different binders, such as road pavement bitu- 
men (Penetration Grade 50/70) and polymer modified bitumen.

\section{Experimental}

The aim of our study was to examine the quality improvement opportunities of bitumen used in road construction (Penetration Grade 50/70). Over the course of our experiments, the modifying effect of a biocomponent derived from pinewood-based fast pyrolysis biooil on the original bitumen 50/70 (B-series) was investigated. Furthermore, experiments that applied the biocomponent together with the block copolymer styrene butadiene styrene (SBS) (P-series) were conducted.

\subsection{Samples}

The investigated feedstock was a commercially-available bitumen (producer: MOL Plc.) with Penetration Grade 50/70 (softening point: $51{ }^{\circ} \mathrm{C}$; penetration: $560.1 \mathrm{~mm}$ ). The modifying agent for the polymer modified bitumen samples was the linear block copolymer styrene butadiene styrene (DST L 30-01, producer: Voronezhsintezkauchuk OJSC) applied at a concentration of $4 \mathrm{w} / \mathrm{w} \%$. The styrene concentration of the copolymer was 30 w/w\%. The applied biocomponent was derived from a commercial pyrolysis liquid of pinewood (producer: BTG-BTL, The Netherlands [31], elemental analysis of the BTG-BTL product: C: $46 \%, \mathrm{H}: 7 \%, \mathrm{O}: 47 \%$; water content: $25 \mathrm{w} / \mathrm{w} \%$ ). Before blending, the sample was stabilised. The water content was removed and the volatile organic components that are boiling up to $220{ }^{\circ} \mathrm{C}$ were removed with the water as well, to adjust the flash point of the additive by distillation. Samples of the biocomponent were applied in concentrations of 1,5 , and $10 \mathrm{w} / \mathrm{w} \%$. Table 1 shows the composition of the samples.

\subsection{Measurements}

In order to characterise our samples, conventional bitumen tests were conducted before and after aging. The softening point of the samples was determined according to the standard MSZ EN 1427 using an automatic ringand-ball softening point tester (Petrotest RKA 5). Penetration measurements were conducted according to the standard MSZ EN 1426 using an automatic penetrometer (Petrotest PNR 12). Aging was simulated by the rolling thin-film oven test (RTFOT) according to the standard MSZ EN 12607-1.

The change in the rheological properties was investigated by using an Anton Paar MCR 301 type dynamic shear rheometer (DSR). The linear viscoelastic range (LVE range) of the samples was investigated by amplitude sweep analysis. During the measurements, the frequency was constant $\left(10 \mathrm{~s}^{-1}\right)$ and the amplitude varied. The amplitude sweep analysis was measured at 10 and $60{ }^{\circ} \mathrm{C}$ which resulted in the corresponding $\gamma$ (deformation) values. The sweep frequency response analysis was
Table 1: Composition of the samples

\begin{tabular}{c|ccc}
\hline \hline $\begin{array}{c}\text { Name of } \\
\text { the sample }\end{array}$ & $\begin{array}{c}\text { Bitumen } \\
50 / 70, \mathrm{w} / \mathrm{w} \%\end{array}$ & $\begin{array}{c}\text { SBS, } \\
\mathrm{w} / \mathrm{w} \%\end{array}$ & $\begin{array}{c}\text { Biocomponent, } \\
\mathrm{w} / \mathrm{w} \%\end{array}$ \\
\hline Bref & 100 & - & - \\
Bbio01 & 99 & - & 1 \\
Bbio05 & 95 & - & 5 \\
Bbio10 & 90 & - & 10 \\
Pref & 96 & 4 & - \\
Pbio01 & 95 & 4 & 1 \\
Pbio05 & 91 & 4 & 5 \\
Pbio10 & 86 & 4 & 10 \\
\hline \hline
\end{tabular}

also investigated at 10 and $60{ }^{\circ} \mathrm{C}$, within the frequency range of $0.01-100 \mathrm{~Hz}$. The multiple stress creep recovery (MSCR) test was performed at $60{ }^{\circ} \mathrm{C}$ over 10 cycles according to the standard ASTM D7405. During the analysis, the samples were subjected to a loading force of 100 $\mathrm{N}$ for $1 \mathrm{sec}$ which was then removed for 9 secs. After the 10 th cycle, the loading force was changed to $3200 \mathrm{~N}$ and another 10 cycles measured. From the experimental values the percentage of the recovery could be calculated.

The temperature-dependence of the rheological properties was investigated within the temperature range of $10-70{ }^{\circ} \mathrm{C}$, with a heating rate of $1^{\circ} \mathrm{C} / \mathrm{min}$ at a constant frequency of $1 \mathrm{~Hz}$. During the measurements, the values of the complex modulus, namely the stiffness and complex viscosity, were investigated.

\section{Results and Analysis}

\subsection{Basic properties}

As for the conventional properties, the softening points of the samples were increased by the biocomponent as well as SBS when compared to the original bitumen 50/70 (Table 2). The increasing effect tendentiously escalated as the amount of applied biocomponent increased. In the case of applying two modifiers simultaneously (biocomponent and SBS polymer), synergistic effects were experienced.

In accordance with the softening points, the penetration of the samples decreased by using every blending component, that is the samples became harder (Table 2). The increased stiffness could be explained by the blending of the rigid biocomponent.

From the results measured after RTFOT, it can be stated that in the case of the SBS polymer modified bitumen $(\mathrm{PmB})$ samples, the aging effect was less significant when compared to the sample of reference bitumen. Moreover, in the case of the PmB samples, the biocomponent enhanced its resistance to hardening. Every sample complied with the technical specifications for road construction currently in force in Hungary (for Bbio samples MSZ EN 12591, for Pbio samples MSZ EN 14023).

Table 2 shows the conventional properties of the samples before and after aging. 
Table 2: Basic properties of the samples and the requirements of the bitumen standards before and after RTFOT.

\begin{tabular}{l|cc|ccc}
\hline \hline & \multicolumn{2}{|c|}{ Before RTFOT } & \multicolumn{3}{c}{ After RTFOT } \\
Increase in \\
\end{tabular}

\subsection{Rheological properties}

The results of the amplitude sweep analysis are presented in Fig. 1.

The deformation values increased by applying the SBS polymer component at $10{ }^{\circ} \mathrm{C}$, thus the LVE ranges were widened. In every case, the blending of the biocomponent narrowed the LVE range. The addition of the rigid component resulted in a stiffer structural material with a lower resistance to deformation. The extent of the decrease was significant in the case of the samples that were only modified with biocomponents. In the other cases, the decrease was less notable, the bituminous matrix could positively compensate for the narrowing effect of the biocomponent.

As for the measurements conducted at $60{ }^{\circ} \mathrm{C}$, the permanent deformation decreased in every case when compared to the reference sample, nevertheless, the value of the permanent deformation increased. In the case of the samples that were only modified with a biocomponent, the narrowing of the LVE ranges was minimal when compared to the values measured at $10{ }^{\circ} \mathrm{C}$.

Fig. 2 shows the results of the sweep frequency response analysis. At $10{ }^{\circ} \mathrm{C}$ and $60{ }^{\circ} \mathrm{C}$, the values of the complex modulus were measured, presented and evaluated at frequencies of $25 \mathrm{~Hz}$ and $30 \mathrm{~Hz}$, respectively. These conditions correlate with similar asphalt tests.

At $10{ }^{\circ} \mathrm{C}$, the complex modulus values, namely the stiffness, were preferably larger in the case of every modified composition when compared to the reference sample (Bref). However, in the case of the samples modified with only a biocomponent, by adding the biocomponent, the stiffness decreased tendentiously. In view of the Bbio10 sample $(10 \mathrm{w} / \mathrm{w} \%)$, the value of the complex modulus was almost identical to that of the reference sample. As for the PmB samples, similar behaviour was observed. By blending the biocomponent in small amounts (up to $5 \mathrm{w} / \mathrm{w} \%$ ), the complex modulus decreased, but in accordance with this effect the fatigue performance improved.
The stiffness of the samples containing $10 \mathrm{w} / \mathrm{w} \%$ of biocomponent (Bbio10 and Pbio10) were comparable to those of the corresponding reference samples (Bref, Pref), thus the stiffness of the asphalt mixture can be suitable as well.

The results measured at $60{ }^{\circ} \mathrm{C}$ showed that the complex modulus positively increased by the blending in of the SBS polymer. In the case of the samples modified with only a biocomponent, the modifying effect of the blending component was negligible.

As for the flexible behaviour, the results of the MSCR test are presented in Figs. 3 and 4. The loaded and relaxation periods are shown in the diagrams on the left-hand side, while the percentage of the elastic recovery at the end of the 1st and 10th cycles can be seen on the right. Every diagram shows the results measured when a loading force of $3200 \mathrm{~N}$ was applied.

In the case of the samples modified with only a biocomponent, the component applied in small concentrations (up to $5 \mathrm{w} / \mathrm{w} \%$ ) influenced the elastic recovery positively when a loading force of $100 \mathrm{~N}$ was applied. However, when applied at a concentration of $10 \mathrm{w} / \mathrm{w} \%$, the percentage of the elastic recovery decreased when compared to the reference sample, however, the value of the permanent deformation increased. When high loading forces $(3200 \mathrm{~N})$ were applied, the permanent deformation was adversely increased by the biocomponent. The elastic recovery of the samples was negligible, the elastic property practically ceased under the test conditions, their viscosity dominated.

In the case of the PmB samples, when a loading force of $100 \mathrm{~N}$ was applied, the biocomponent influenced the flexible behaviour positively at every concentration. The permanent deformation decreased and, in line with this positive effect, the percentage of the elastic recovery increased. Thus, the rutting performance of the samples was favourable. The higher the blending concentration of the biocomponent was, the more flexible the behaviour 

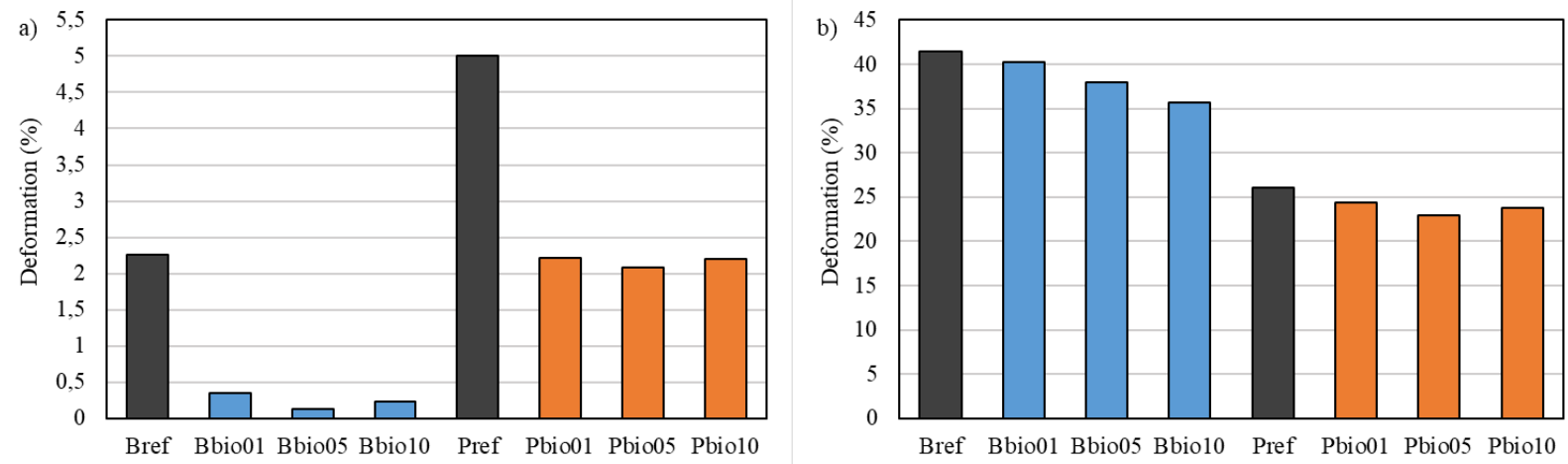

Figure 1: LVE range of the samples - a) $10^{\circ} \mathrm{C}$, b) $60^{\circ} \mathrm{C}$.
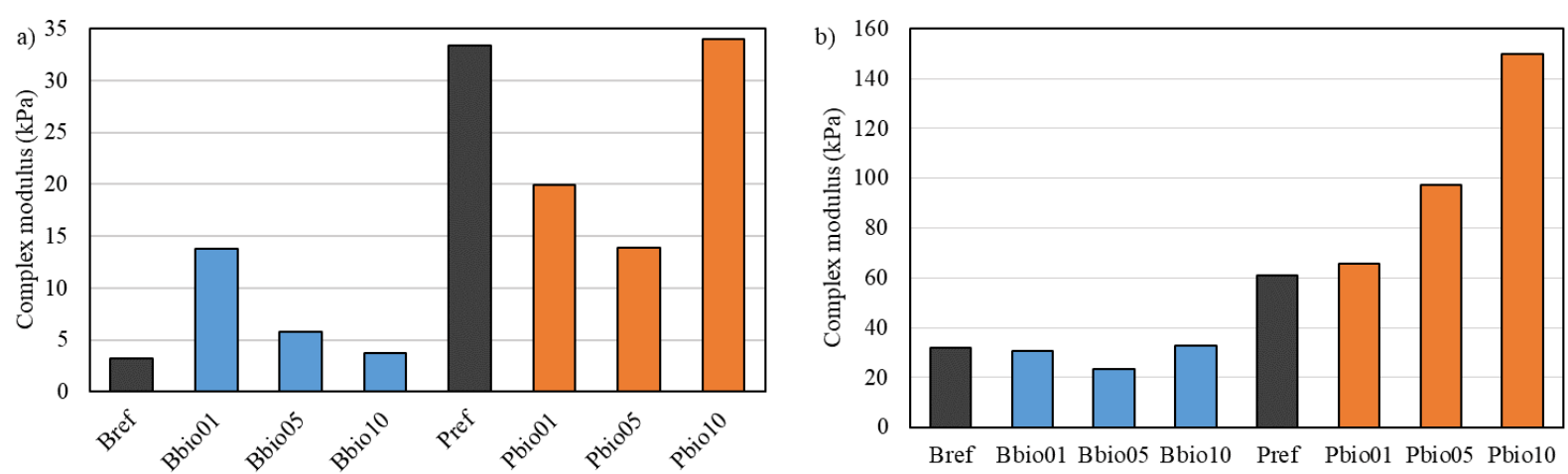

Figure 2: Complex modulus of the samples - a) $10^{\circ} \mathrm{C}, 25 \mathrm{~Hz}$ frequency, b) $60^{\circ} \mathrm{C}, 30 \mathrm{~Hz}$ frequency.
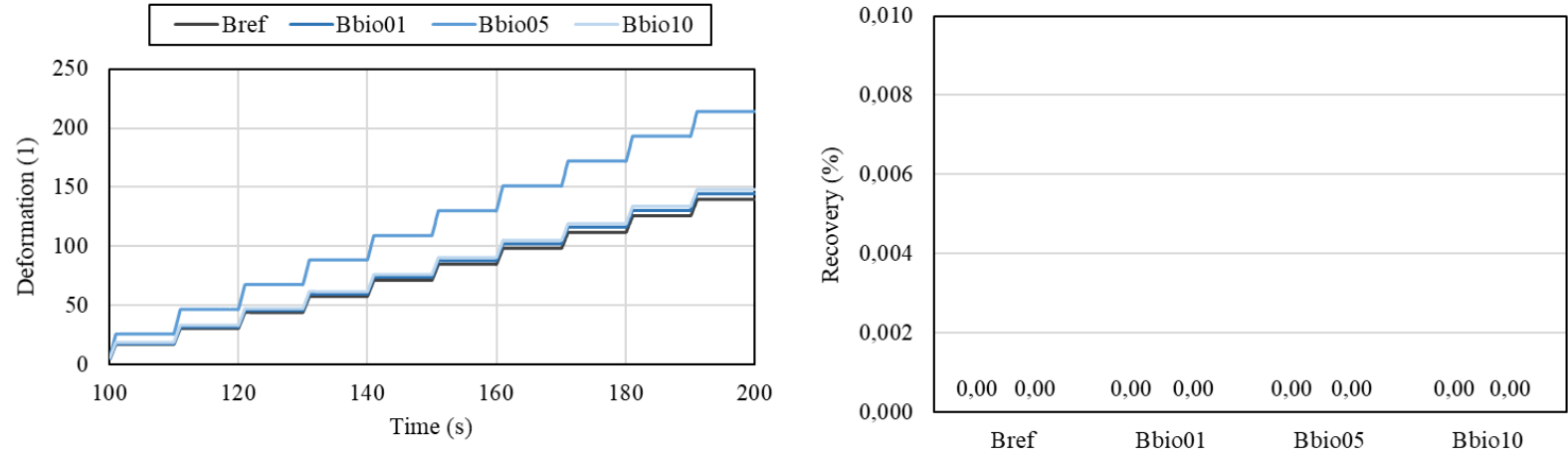

Figure 3: The results of the MSCR test of the samples modified with only a biocomponent when subjected to a loading force of $3200 \mathrm{~N}$.

it exhibited. When high loading forces were applied, the tendency was the same. The favourable values of the PmB samples can be explained by a phenomenon in which the biocomponent did not influence the flexible properties of the PmB matrix, while it could mitigate the liability to deform as a result of its rigid structure.

By comparing the values of every sample measured by the MSCR test, the flexible behaviour of the PmB samples was significantly better than in the case of the reference bitumen sample. Nowadays the modification of bitumen is strictly necessary in order to comply with the more rigid requirements enforced by the technical practices of road construction, namely that the binders have a sufficient degree of rutting performance. According to our measurements, the biocomponent by itself cannot provide a good solution to this problem, however, by blending it with SBS polymer the modifying effect of the biocomponent could be beneficial.

The results of the Temperature Sweep Analysis are presented in Fig. 5. In the case of the samples that were only modified with the biocomponent, the values of the complex modulus decreased at lower concentrations (up to $5 \mathrm{w} / \mathrm{w} \%$ ), but by applying the biocomponent at 10 $\mathrm{w} / \mathrm{w} \%$, the values of the complex modulus were almost identical to that of the reference sample (Bref).

As for the PmB samples, the stiffness increased in every case when compared to the Bref sample. The value of the complex modulus increased by increasing 

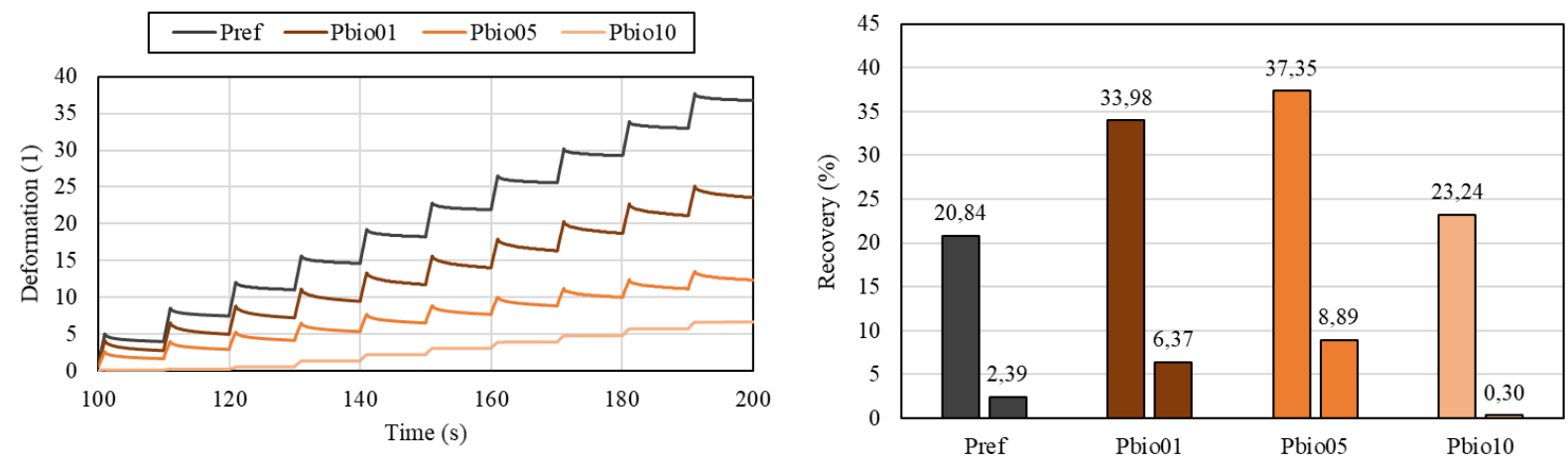

Figure 4: The results of the MSCR test of the samples modified with SBS polymer when subjected to a loading force of $3200 \mathrm{~N}$.

the biocomponent concentration. During the Temperature Sweep Analysis, the temperature dependence of the complex viscosity was measured as well. The tendency was very similar to that of the temperature dependence of the complex modulus. In particular, the complex viscosity significantly increased in the case of the PmB samples when compared to the reference sample (Bref). By increasing the blending concentration of the biocomponent, the complex viscosity increased further.

\section{Conclusion}

The aim of this work was to investigate the quality improvement opportunities of bitumen used in road construction (Penetration Grade 50/70) and to provide a com-
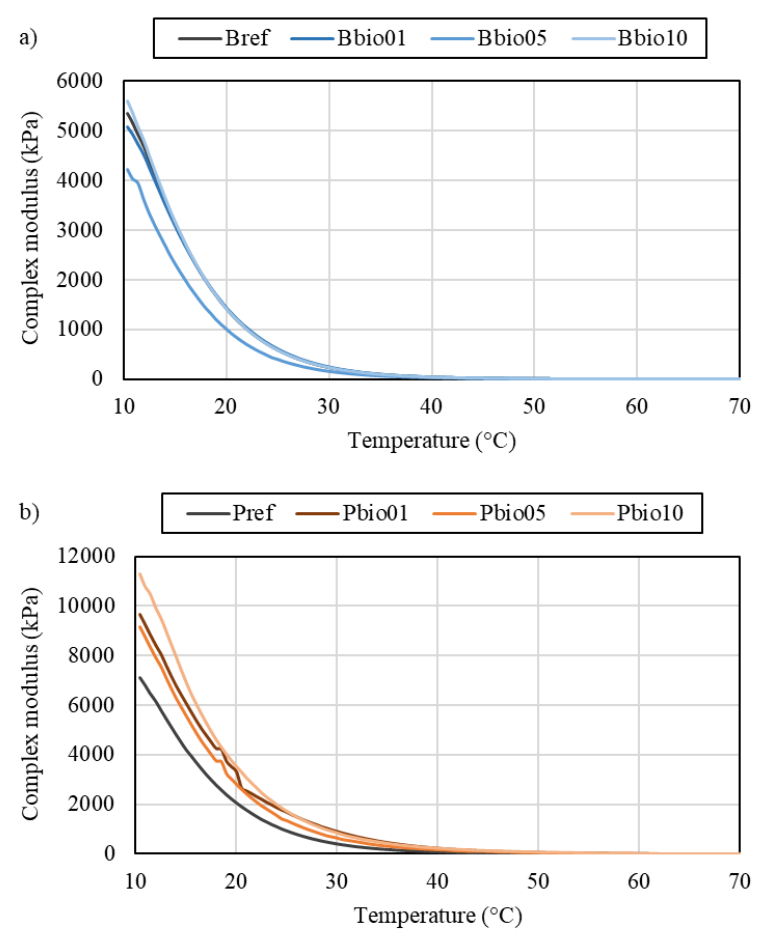

Figure 5: Temperature dependency of complex viscosity - a) samples modified only with biocomponent, b) PmB samples. parative analysis of the modifying effect of stabilised pinewood-based fast pyrolysis bio-oil on SBS polymer modified bitumen. According to our measurements, the biocomponent can be blended at a concentration of 10 w/w\% with the tested bituminous binders. As for its flexible properties, the utilisation of the biocomponent by itself does not result in a good bitumen quality, but together with the SBS polymer the rutting performance improves significantly. Based on these results, further measurements are being planned with other modifying agents to identify the exact and credible binder composition from economical and technical points of view. Furthermore, it is necessary to examine the methods of blending and treating opportunities of the biocomponent that can produce a binder with better mechanical properties and possibly with a greater concentration of the biocomponent in the blend.

\section{Acknowledgements}

This research was supported by the ÚNKP-18-2 New National Excellence Program of the Ministry of Human Capacities. The authors thank MOL Plc. providing the bitumen sample.

\section{REFERENCES}

[1] Read, J.; Whiteoak, D.: The shell bitumen handbook (Thomas Telford, London, UK, 2003) ISBN:0 7277 $3220 \mathrm{X}$

[2] Geiger, A.; Holló, A.; Fehér, P.: MOL Rubber bitumen-Part 1. MOL Group Scientific Magazine 2012/2, 54-61 DOI: 10.24193/subbchem.2017.2.19

[3] Holló, A.; Geiger, A.; Gergó, P.: (2017). Upgrading options of heavy residues, rubber modified bitumen case study. Fuels and Lubricants, 1(1), 1823. https://www. yumpu.com/en/document/read/ $59539765 /$ fuels-lubricants-magazine

[4] Angyal, A., Miskolczi, N., Bartha, L., Gergo, P. Synthesis and evaluation of modified polyethylene wax applied as dispersant in rubber bitumen composites. Hung. J. Ind. Chem., 2009, 37(1), 21- 
25 https://mk.uni-pannon.hu/hjic/index.php/ hjic/article/view/217

[5] Adorjányi, K., Füleki, P. Performance evaluation of bitumens at high temperature with multiple stress creep recovery test. Hung. J. Ind. Chem., 2011, 39(2), 195-199. https://mk. uni-pannon. hu/hjic/index.php/hjic/article/view/409

[6] Yang, X., You, Z., Dai, Q., Mills-Beale, J. Mechanical-performance of asphalt mixtures modified by bio-oils derived from waste wood resources. Construction and Building Materials, 2014, 51, 424-431 DOI: 10.1016/j.conbuildmat.2013.11.017

[7] Chailleux, E., Audo, M., Bujoli, B., Queffelec, C., Legrand, J., Lepine, O. Alternative Binder from microalgae: Algoroute project. Workshop: Alternative binders for sustainable asphalt pavements, 2012, pp. 7-14.

[8] Fini, E. H., Kalberer, E. W., Shahbazi, A., Basti, M., You, Z., Ozer, H., Aurangzeb, Q. Chemical characterization of biobinder from swine manure: Sustainable modifier for asphalt binder. Journal of Materials in Civil Engineering, 2011, 23(11), 1506-1513 DOI: 10.1061/(ASCE)MT.1943-5533.0000237

[9] Mills-Beale, J., You, Z., Fini, E., Zada, B., Lee, C. H., Yap, Y. K. Aging influence on rheology properties of petroleum-based asphalt modified with biobinder. Journal of Materials in Civil Engineering, 2012, 26(2), 358-366 DOI: 10.1061/(ASCE)MT.1943-5533.0000712

[10] Raouf, M. A., Williams, R. C. Rheology of fractionated cornstover bio-oil as a pavement material. International Journal of Pavements, 2010, 9, 58-69

[11] Hill, D. R., Jennings, A. A. (2011). Bioasphalt from Urban Yard Waste Carbonization. A Student Study for the Ohio Department of Transportation Office of Research and Development (State Job Number 134464) https://rosap.ntl.bts.gov/view/dot/ 23358/dot_23358_DS1.pdf?

[12] Uzun, B. B., Apaydin-Varol, E., Ateş, F., Özbay, N., Pütün, A. E. Synthetic fuel production from tea waste: characterisation of bio-oil and bio-char. Fuel, 2010, 89(1), 176-184 DOI: 10.1016/j.fuel.2009.08.040

[13] Chaiya, C. Production of bio-oil from coffee residue using pyrolysis process. 2010, Proceedings of the World Congress on Engineering and Computer Science (Vol. 2), pp. 19-21. http://www.iaeng.org/publication/ WCECS2011/WCECS2011_pp704-707.pdf

[14] Onay, O., Koçkar, O. M. Pyrolysis of rapeseed in a free fall reactor for production of bio-oil. Fuel, 2006, 85(12), 1921-1928., DOI: 10.1016/j.fuel.2006.03.009

[15] Ţensöz, S., Kaynar, Ý. Bio-oil production from soybean (Glycine max L.); fuel properties of Bio-oil. Industrial Crops and Products, 2006, 23(1), 99-105 DOI: 10.1016/j.indcrop.2005.04.005

[16] Ingrassia, L. P., Lu, X., Ferrotti, G., Canestrari, F. Renewable materials in bituminous binders and mixtures: Speculative pretext or reliable opportunity?. Resources, Conservation and Recycling, 2019, 144, 209-222 DOI: 10.1016/j.resconrec.2019.01.034

[17] Peralta, J., Williams, R. C., Rover, M., Silva, H. M. R. D. Development of rubber modified fractionated bio-oil for use as noncrude petroleum binder in flexible pavements. 2012, Transportation Research Circular E-C165: Alternative Binders, pp. 23-36. https://repositorium.sdum. uminho.pt/bitstream/1822/22357/1/Artigo_ TRB-Circular-ec165-mypaper.pdf

[18] Peralta, J., Williams, R. C., Silva, H. M., Machado, A. V. Combining Asphalt T-Rubber (AR) and FastPyrolysis Bio-Oil to Create a Binder for Flexible Pavements. 2013, Proceedings of the 2nd Edition of the International Conference and Exhibition WASTES: Solutions, Treatments and Opportunities, pp. 1-8. https://pdfs.semanticscholar.org/ 9909/205f9c3af88eb53e053aa09ddlec53fe73e1. pdf?_ga $=2.105672513 .336972856$. 1576827673-1545734105.1576827673

[19] Peralta, J., Williams, R. C., Silva, H. M., Machado, A. V. A. Recombination of asphalt with bio-asphalt: Binder formulation and asphalt mixes application. Journal of the Association of Asphalt Paving Technologists, 2014, 83, 1-25.

[20] Grilli, A., Bocci, E., Bocci, M. Hot recycling of reclaimed asphalt using a bio-based additive. In 8th RILEM International Symposium on Testing and Characterization of Sustainable and Innovative Bituminous Materials, (Springer, Dordrecht, 2016), pp. 953-964 DOI: 10.1007/978-94-017-7342-3_76

[21] Jiménez del Barco Carrión, A., Lo Presti, D., Pouget, S., Airey, G., Chailleux, E. Linear viscoelastic properties of high reclaimed asphalt content mixes with biobinders. Road Materials and Pavement Design, 2017, 18(sup2), 241-251., DOI: 10.1080/14680629.2017.1304253

[22] Jiménez del Barco Carrión, A., Pérez-Martínez, M., Themeli, A., Lo Presti, D., Marsac, P., Pouget, S., ... Airey, G. Evaluation of bio-materials' rejuvenating effect on binders for high-reclaimed asphalt content mixtures. Materiales de Construcción, 2017, 67(327), 1-11 DOI: 10.3989/mc.2017.04516

[23] Lei, Z., Bahia, H., Yi-qiu, T., Ling, C. Effects of refined waste and bio-based oil modifiers on rheological properties of asphalt binders. Construction and Building Materials, 2017, 148, 504-511 DOI: 10.1016/j.conbuildmat.2017.05.101

[24] Raouf, M. A., Williams, R. C. Temperature and shear susceptibility of a nonpetroleum binder as a pavement material. Transportation Research Record, 2010, 2180(1), 9-18 DOI: 10.3141/2180-02

[25] Cooper III, S. B., Mohammad, L. N., Elseifi, M. Evaluation of asphalt mixtures containing renewable binder technologies. International Journal of Pavement Research and Technology, 2013, 6(5), 570-575 DOI: 10.6135/ijprt.org.tw/2013.6(5).570 
[26] Ball, G. F. A., Herrington, P. A., Patrick, J. E.. Tall oil pitch as bitumen extender. New Zealand Journal of Forestry Science, 1993, 23(2), 236-242 https://www.scionresearch. com/_data/assets/pdf_file/0016/17701/ NZJFS2321993BALL236-242.pdf

[27] Bearsley, S. R., Haverkamp, R. G. Age hardening potential of tall oil pitch modified bitumen. Road Materials and Pavement Design, 2007, 8(3), 467481 DOI: 10.1080/14680629.2007.9690084

[28] Bearsley, S. R., Haverkamp, R. G. Adhesive properties of tall oil pitch modified bitumen. Road Materials and Pavement Design, 2007, 8(3), 449-465 DOI: 10.1080/14680629.2007.9690083
[29] Gondim, L. M., Soares, S. A., Barroso, S. H. Petroleum Plant Sap as an Asphalt Modifier for Pavement Applications. International Journal of Engineering \& Technology IJCEE-IJENS, 2006, 16(06)

[30] Yang, X., Mills-Beale, J., You, Z. Chemical characterization and oxidative aging of bio-asphalt and its compatibility with petroleum asphalt. Journal of Cleaner Production, 2017, 142, 1837-1847 DOI: 10.1016/j.jclepro.2016.11.100

[31] BTG-BTL, Pyrolysis oil properties. https://www . btg-btl.com/en/applications/oilproperties (Accessed: 11/06/2019) 